
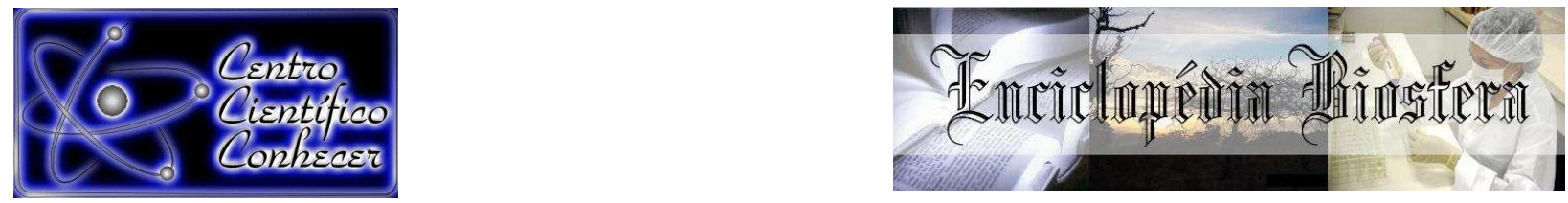

\title{
IMPACTOS AMBIENTAIS EM ÁREAS DE PRESERVAÇÃO PERMANENTE DE CENTROS URBANOS: O CASO DA BACIA DO CÓRREGO LISO EM UBERLÂNDIA
}

\author{
Isabelle Marian Lacorte1, Maria Rita Raimundo e Almeida² \\ 1 Graduada em Engenharia Ambiental pela Universidade Federal de Uberlândia \\ (isabelle lacorte@hotmail.com) Uberlândia - Minas Gerais \\ 2 Profa Doutora do Instituto de Ciências Agrárias da Universidade Federal de \\ Uberlândia \\ Recebido em: 08/09/2015 - Aprovado em: 14/11/2015 - Publicado em: 01/12/2015 \\ DOI: http://dx.doi.org/10.18677/Enciclopedia_Biosfera_2015_175
}

\begin{abstract}
RESUMO
A preservação e as intervenções provocadas em Áreas de Preservação Permanente (APP) de ambientes urbanos são questões de relevância devido à falta de áreas de vegetação encontradas atualmente nas cidades, o que tem agravado problemas como enchentes e instabilidades de encostas que, por sua vez, causam efeitos adversos na população. A finalidade do presente trabalho foi realizar uma análise destas questões na bacia do córrego Liso no Município de Uberlândia, que apresenta diferentes formas de uso e ocupação do solo, abrangendo bairros de uso residencial e industrial. Para a consolidação do trabalho foi utilizado o Programa ArcGis versão 10.1, onde foram feitas as delimitações tanto da bacia quanto das APPs segundo o Novo Código Florestal. Ainda através do software foram identificadas três classes de uso do solo na bacia em estudo - vegetação, pastagem e uso urbano - sendo comparadas imagens dos anos de 1964 e 2010. Verificou-se que a quantidade de vegetação dentro da área de APP é maior no ano de 2010 em comparação com 1964. Mesmo assim, dois quintos da área que deveria ser coberta por vegetação sofre ocupações irregulares, com atividades bastante impactantes para a área.
\end{abstract}

PALAVRAS-CHAVE: ArcGis. Novo Código Florestal. Uso e ocupação do solo.

\section{ENVIRONMENTAL IMPACTS IN PERMANENT PRESERVATION AREAS OF URBAN CENTERS: THE CASE OF CÓRREGO LISO WATERSHED IN UBERLÂNDIA}

\begin{abstract}
The preservation and interventions caused in Permanent Preservation Areas (PPA) of urban environments are very important issues due to lack of vegetation areas currently found in cities, which has exacerbated problems such as flooding and slope instabilities that, in turn, cause adverse effects in population. The purpose of this work was to analyze these issues in watershed Córrego Liso in Uberlândia, that presents different forms of land use and occupation, including neighborhoods of residential and industrial use. To consolidate the work it was used the ArcGIS program version 10.1, where they were asked the delimitations of the basin and the PPA according to the New Forest Code. Still through the software it was identified
\end{abstract}


three land use classes for the study watershed - vegetation, pasture and urban use being compared images of the years 1964 and 2010. Was verified that the amount of vegetation inside PPA area is higher in 2010 compared to 1964. Still, two-fifths of the area that should be cover by vegetation, suffers irregular occupations, with plenty impactful activities to the area.

KEYWORDS: ArcGis. New Florestal Code. Land use and occupation.

\section{INTRODUÇÃO}

Até as décadas de 1950/1960, a poluição era vista como um indicador de desenvolvimento, até que a manifestação de problemas ambientais em meados de 1960, como a inversão térmica ocorrida em Londres e a contaminação por mercúrio na baia de Minamata no Japão, fizeram as pessoas perceberem que tinham que mudar o comportamento e adotar práticas mais sustentáveis (HOGAN, 2006).

Assim, foi fundamental o seguimento de regras de condutas que visem à evolução organizacional, permitindo as mais adequadas apropriações dos recursos naturais (FORNO, 2009). Surgiu então o conceito de desenvolvimento sustentável, entendido como o desenvolvimento que satisfaz as necessidades do presente sem prejuízo das gerações futuras (RELATÓRIO DE BRUNDTLAND, 1987).

Visando esta apropriação mais adequada dos recursos, as legislações dos diferentes países procuraram criar áreas voltadas para a preservação da natureza. No Brasil, entre elas, as Áreas de Preservação Permanente (APP), que foram instituídas pela Lei Federal no 4.771, de 1965, conhecida como Código Florestal, recentemente, alterada pela Lei Federal $n^{\circ} 12.651$, de 25 de Maio de 2012. Segundo esta legislação, APP é uma área protegida, coberta ou não por vegetação nativa, com a função ambiental de preservar os recursos hídricos, a paisagem, a estabilidade geológica e a biodiversidade, facilitar o fluxo gênico de fauna e flora, proteger o solo e assegurar o bem-estar das populações humanas (BRASIL, 2012).

As APPs podem estar presentes tanto em áreas rurais como urbanas. Nestas últimas, sua aplicabilidade é dificultada pela degradação e o impacto que elas sofrem. ARAUJO (2002) comenta que esses impactos são causados, principalmente, por ação antrópica, sendo a população que vive ao redor dessas áreas as que mais as degradam. A degradação pode ser através de poluição, ao jogarem resíduos no local de forma inapropriada, pelas indústrias que descartam resíduos, tanto líquidos como sólidos, pelas pessoas que se alojam nessas áreas e constroem moradias, entre outros. A questão da moradia nessas áreas é complicada por apresentar tanto o risco de degradação da área com supressão da vegetação nativa, como risco àquelas próprias pessoas que estão se alojando nestes lugares.

Para identificar e entender os cenários de degradação destas áreas tem sido utilizada a tecnologia do Sensoriamento Remoto que, segundo ELACHI (1987), é a obtenção de informações através da determinação e mensuração das alterações causadas por um objeto aos campos de força que o rodeiam, podendo ser estes campos tanto eletromagnético, como acústico ou potenciais. O mesmo autor considera que a definição mais geral e abrangente seria a aquisição de informação sobre um objeto sem que se entre em contato físico com este.

O sensoriamento remoto é uma metodologia muito importante na gestão urbana, pois é através desta que são quantificados e determinados detalhes de uma região (BORSOI \& JUNIOR, 2009). Através deste método pode-se avaliar os parâmetros de qualidade ambiental e, assim perceber a extensão das APPs em uma região e identificar os tipos de ocupação do solo. Essa tecnologia envolve a disponibilidade das imagens orbitais obtidas de alta frequência temporal, dispostos 
em forma digital, que aliadas ao Sistema de Informação Geográfica (SIG), possibilitam o monitoramento da área urbana (BORSOI \& JUNIOR, 2009).

BONHAN-CARTER (1996) entende Sistema de Informações Geográficas (SIG) como um sistema de software computacional que possibilita que uma dada informação seja capturada, armazenada e analisada; o SIG pode combinar os dados espaciais de diferentes fontes em uma base unificada, estabelecendo diferentes composições digitais que representam fenômenos espaciais distintos, por uma série de planos de informação que se sobrepõem corretamente em qualquer ponto definido. Em uma definição mais atual LONGLEY et al. (2013) referem-se ao mesmo sistema como uma classe especial de sistemas de informação que além de controlar eventos, atividades e coisas, também controlam onde estes acontecem ou existem.

Neste trabalho foi escolhida como área de estudo a bacia do córrego Liso, localizada no município de Uberlândia, por ser uma bacia com diferentes formas de uso e ocupação do solo devido à bacia encontrar-se em um perímetro que abrange bairros de uso industrial e residencial e, sendo assim, sofre impactos ocasionados tanto pela população das residências como pelas indústrias ali instaladas (SILVA, 2006).

O objetivo principal do presente trabalho foi diagnosticar a situação de preservação das APPs estabelecidas pela Lei Federal n¹2.651 de 2012 (B RASIL, 2012), dentro da bacia do córrego Liso e identificar as atividades que estão impactando esta área, utilizando-se da tecnologia de Sensoriamento Remoto e SIG. Também foi objetivo da presente pesquisa caracterizar a diferença entre as áreas de preservação do município de Uberlândia na década de 1960 e atualmente (ano de 2010).

\section{Área de estudo}

\section{MATERIAL E MÉTODOS}

A cidade de Uberlândia está localizada no estado de Minas Gerais, no entroncamento entre o sudeste, norte e centro-oeste do Brasil. Segundo o IBGE (2014), Uberlândia é uma região que tem se desenvolvido muito, com uma área de aproximadamente $4.115 \mathrm{~km}^{2}$ e uma população no ano de 2013 maior que 600 mil habitantes. A Polícia Civil da cidade acusa que a população é de aproximadamente 800 mil habitantes.

Visando obter informações sobre a modificação das APP dentro das áreas urbanas do município de Uberlândia, a bacia do córrego Liso foi escolhida, já que a mesma está localizada no setor norte da cidade, nos arredores do Bairro Distrito Industrial, o qual é o polo industrial do município e também abrange áreas de uso residencial. De acordo com SCHNEIDER (1996), o córrego Liso é um dos efluentes da margem direita do Rio Uberabinha, que é o principal responsável pelo abastecimento de água da cidade de Uberlândia. A bacia do córrego Liso está localizada nas coordenadas geográficas 4895'31" a 4891' de longitude oeste e de 1851'27" a 1853'48' de latitude sul, com área d e 15,78 km², representando aproximadamente $7,73 \%$ da área urbana do município de Uberlândia (PERES, 2005).

O mesmo córrego apresenta duas nascentes, uma próxima à Avenida Arcírio Cardoso da Silva e Avenida Clara Camarão com a Rua Piauí, e outra entre a Rua Pedro Quirino Silva e Avenida Padre Miguelino, entre os bairros Nossa Senhora das Graças e Cruzeiro do Sul e percorre os bairros Residencial Gramado, Distrito Industrial, Pacaembu e Maravilha, e deságua no Rio Uberabinha, próximo à Rua Coronel José Teófilo Carneiro (SILVA, 2006). O córrego Liso apresenta uma 
ramificação, um afluente, que é a sub-bacia conhecida como córrego Buritizinho, que está destacado na Figura 1. Na mesma figura é possível observar a localização da bacia do córrego Liso na região, com o destaque para os bairros de relevante influência no córrego.

Na Figura 1, é possível notar que a vazão do córrego Liso é descarregada no Rio Uberabinha, que é o rio utilizado como fonte de abastecimento de toda cidade de Uberlândia.

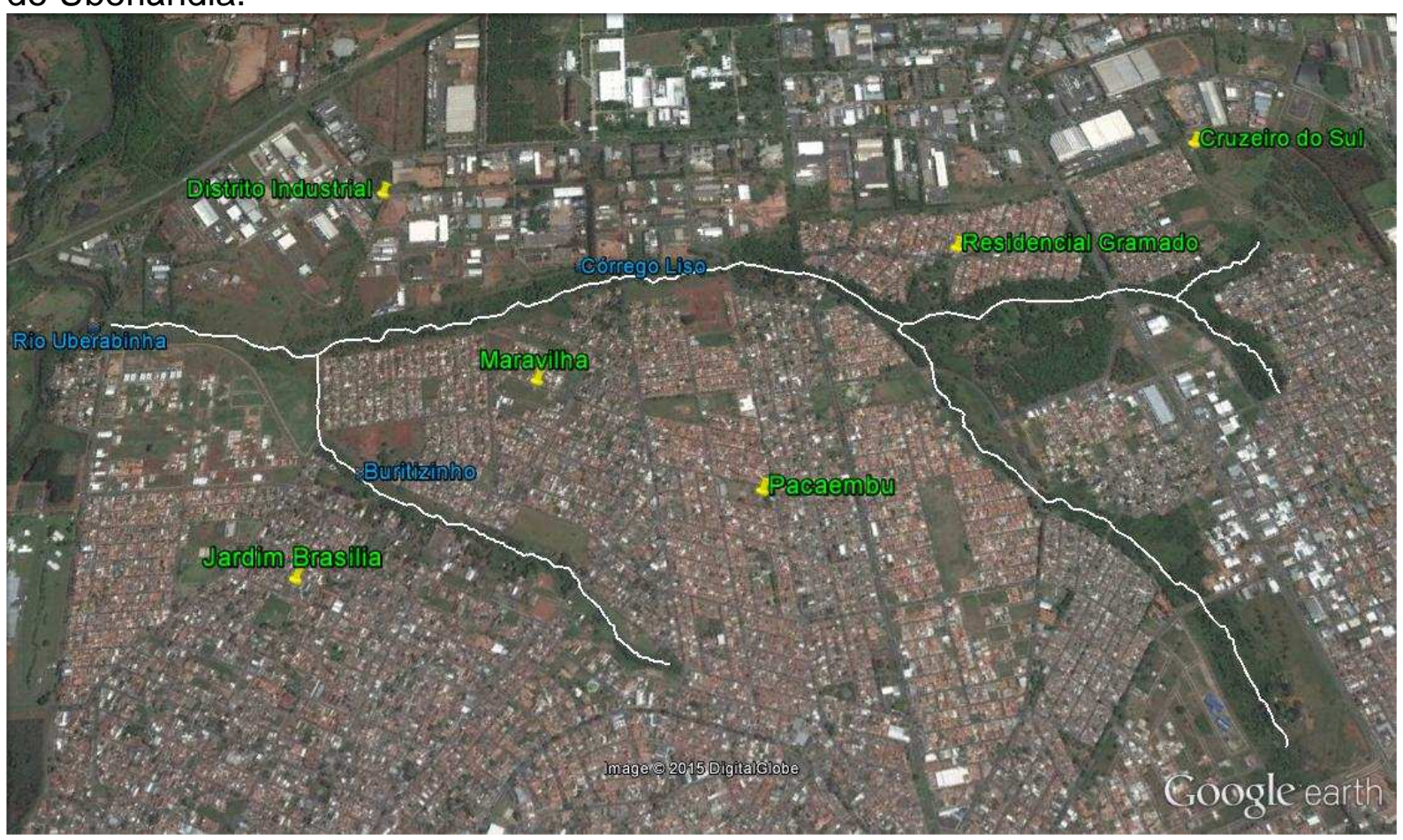

FIGURA 1- Localização do Córrego Liso e a Região de Influência. Imagem Google Earth, 2014.

\section{Procedimentos Metodológicos}

Foi realizada a delimitação da bacia do córrego Liso através do programa ArcGIS versão 10.1 com cartas topográficas obtidas no Laboratório de Cartografia e Sensoriamento Remoto do Instituto de Geografia da Universidade Federal de Uberlândia.

As imagens a serem utilizadas no trabalho foram encontradas no site do Instituto Nacional de Pesquisas Espaciais (INPE), no link Catálogo de Imagens, e no Laboratório de Cartografia e Sensoriamento do Instituto de Geografia da Universidade Federal de Uberlândia. A imagem mais atual, do ano de 2010, foi obtida pelo satélite Rapideye AG, que atualmente é conhecido por BlackBridge. Esse satélite consiste em uma constelação de cinco micro-satélites lançado em 2008, e controlado pela empresa Alemã Brandenburg an der Havel. Já a imagem de 1964, foi uma foto aérea de número 48610, obtida através do Instituto Brasileiro de Café - IBC por meio do USAF (United State Air Force). A escala das imagens está em 1:1.000.000, em que $1 \mathrm{~cm}$ do mapa equivale a $10 \mathrm{~km}$ no terreno.

Os anos de análise (1964 e 2010) foram escolhidos em função da disponibilidade de imagens gratuitas e que possuíam a resolução necessária para a execução do trabalho. Inicialmente, a imagem foi georreferenciada com a identificação das coordenadas latitude e longitude de pontos estipulados dentro da área da bacia. Foi realizado o contorno da drenagem da bacia do córrego Liso, possibilitando conhecer a largura do rio $(13 \mathrm{~m})$ e, a partir desta, definir através de ENCICLOPÉDIA BIOSFERA, Centro Científico Conhecer - Goiânia, v.11 n.22; p.1467 2015 
comando específico, o tamanho da APP a ser inserida ao redor da drenagem, de acordo com o Novo Código Florestal (Lei Federal n 12.651 de 2012), sendo esta de 50 metros. Ainda foram consideradas as APPs de nascentes com um raio de $50 \mathrm{~m}$.

Em seguida, foram mapeadas e identificadas três classes de uso do solo dentro da bacia, sendo elas: vegetação, que é a vegetação de porte arbustivo e/ou arbóreo da APP; a pastagem, que é considerada a vegetação rasteira, ou ainda áreas cobertas com grama; e urbanização, que categoriza o uso e ocupação do solo como habitações e construções civis, ou ainda solo exposto.

O procedimento envolveu delimitações através de polígonos, assim, somouse a área de todos os polígonos para cada classe. Os valores calculados pelo programa foram analisados e comparados através dos mapas de cada ano e de gráfico que mostra as porcentagens de cada classe de uso do solo em cada imagem.

Por fim, para verificar quais as principais atividades que causam impactos na bacia do córrego Liso, foram realizadas visitas de campo. Foram três dias de visitação aos locais (11 a 13/08/2014). No primeiro dia foi visitada a região do Buritizinho; no segundo, o corpo do córrego Liso, desde o local onde o córrego Liso deságua no Uberabinha até encontro das ramificações, próximo à Rua Ignês Favato; e, no terceiro, foi visitada a continuação do córrego ao longo da Rua José Eduardo Gadia. Durante as visitações o objetivo era identificar as principais atividades impactantes realizadas dentro das áreas de APP.

\section{RESULTADOS E DISCUSSÃO}

Na Figura 2 é apresentada a ocupação da bacia do Córrego Liso no ano de 1964 e, na Figura 3, a ocupação da mesma bacia no ano de 2010.
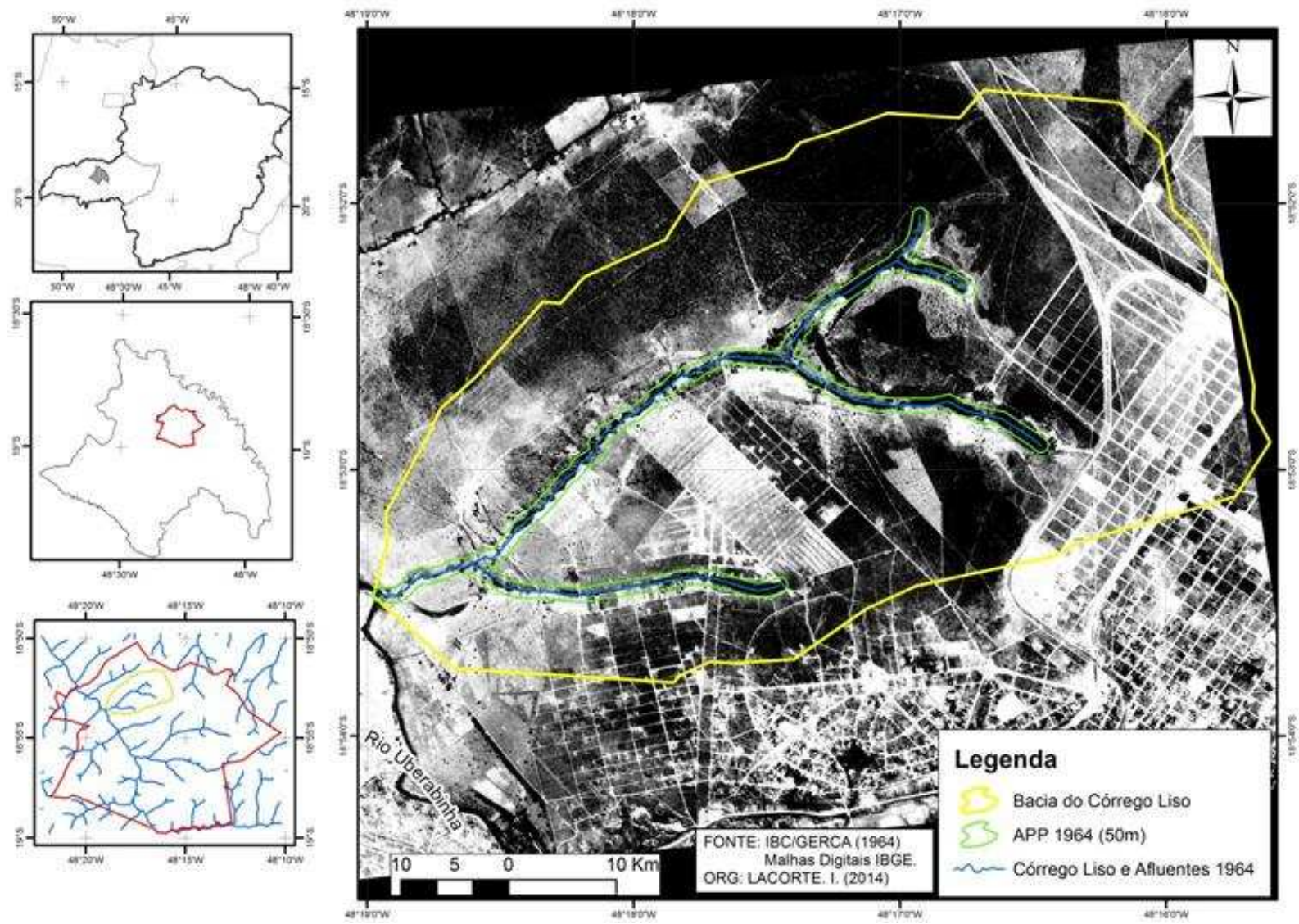

FIGURA 2- Mapa da Bacia do Córrego Liso em imagem do ano de 1964. Fonte: As Autoras. 
Na Figura 2, é possível observar a delimitação da bacia do córrego Liso dentro do perímetro urbano de Uberlândia, com o contorno do rio e das APPs de margem de rio e de nascentes. Nesta imagem, pode-se analisar que a cidade de Uberlândia ainda não era tão ocupada, com pouca área construída, sendo possível identificar uma cidade ainda em formação, com potencial de desenvolvimento. Já a Figura 3 apresenta a mesma região 46 anos depois. Observa-se que a região ao redor da bacia está toda ocupada por prédios e construções que não existiam em 1964, sendo assim, a urbanização ao redor da bacia intensificou-se ao longo dos anos.
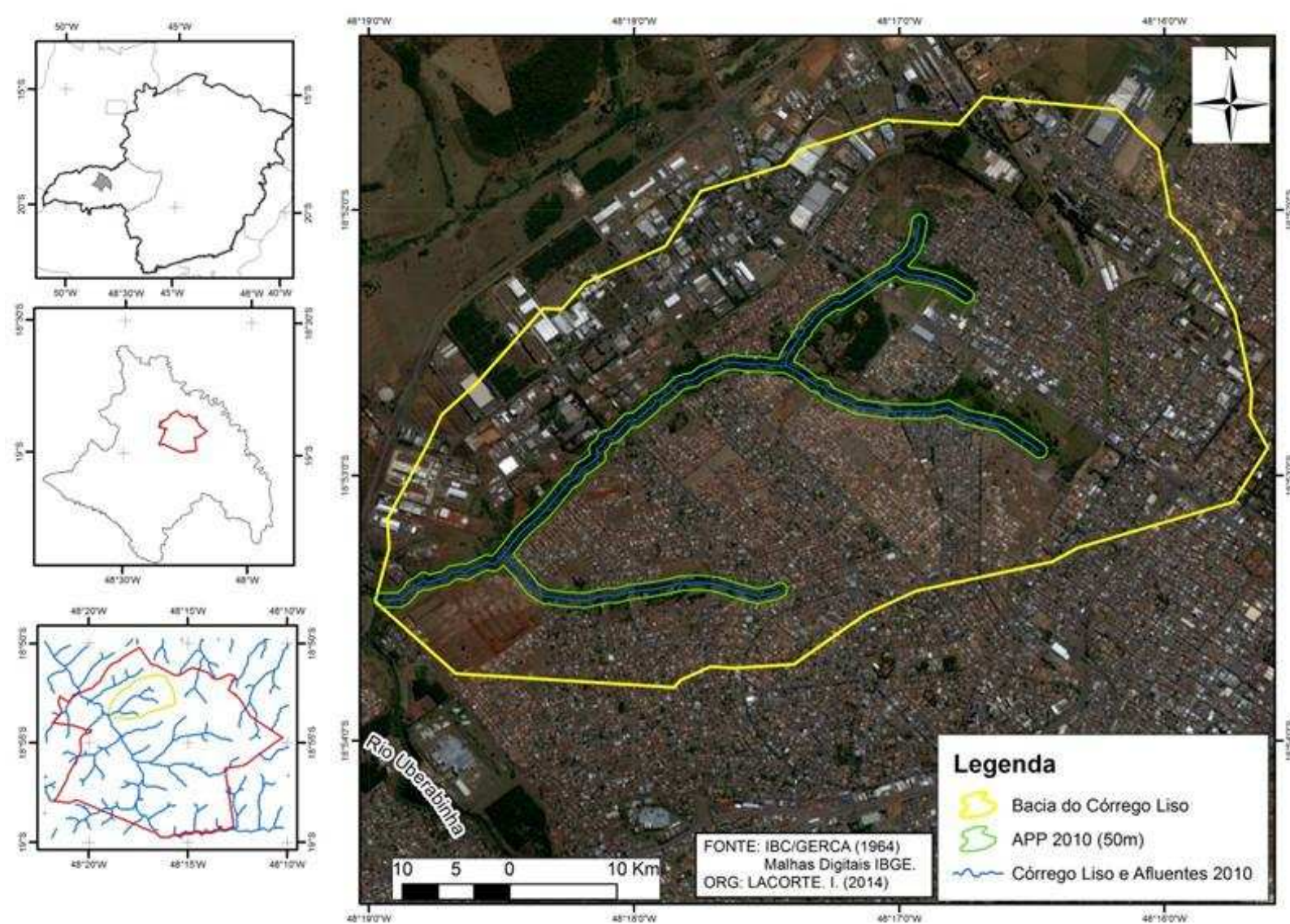

FIGURA 3- Mapa da Bacia do Córrego Liso em imagem do ano de 2010. Fonte: As Autoras.

Através do processo de mapeamento foram identificadas três classes de uso do solo, sendo: vegetação, urbanização e pastagem, que podem ser visualizadas na Figura 4 (ano de 1964) e na Figura 5 (ano de 2010). Os polígonos de cor vermelha apresentam a classe pastagem, o uso urbano do solo é representado pela cor rosa e, por fim, a cor verde representa a vegetação da APP. Em 1964 (Figura 4), a área de APP era ocupada por 36,43 ha de pastagem, 13,17 ha de uso urbano e 43,53 ha de vegetação. Assim, a área total de APP neste ano é 93,13 ha. É possível notar que boa parte da área total de APP é tomada por pastagem ou vegetação rasteira.

Em 2010 (Figura 5), a área total de APP dessa região era de 91,75 ha, sendo, portanto, uma área pouco menor do que a da imagem de 1964. Isso se deve ao fato de ter ocorrido uma retilinização de parte do córrego, na porção inicial do Buritizinho, sendo assim, a delimitação da APP, na imagem de 1964, foi feita considerando-se a área anterior à transposição, o que trouxe uma diferença de aproximadamente 1,4 
ha na área total da APP entre as duas delimitações. Com relação às classes de solo em 2010, estas correspondiam em termos de área a 18,89 ha de pastagem, 15,91ha de uso urbano e 56,95 ha de vegetação.

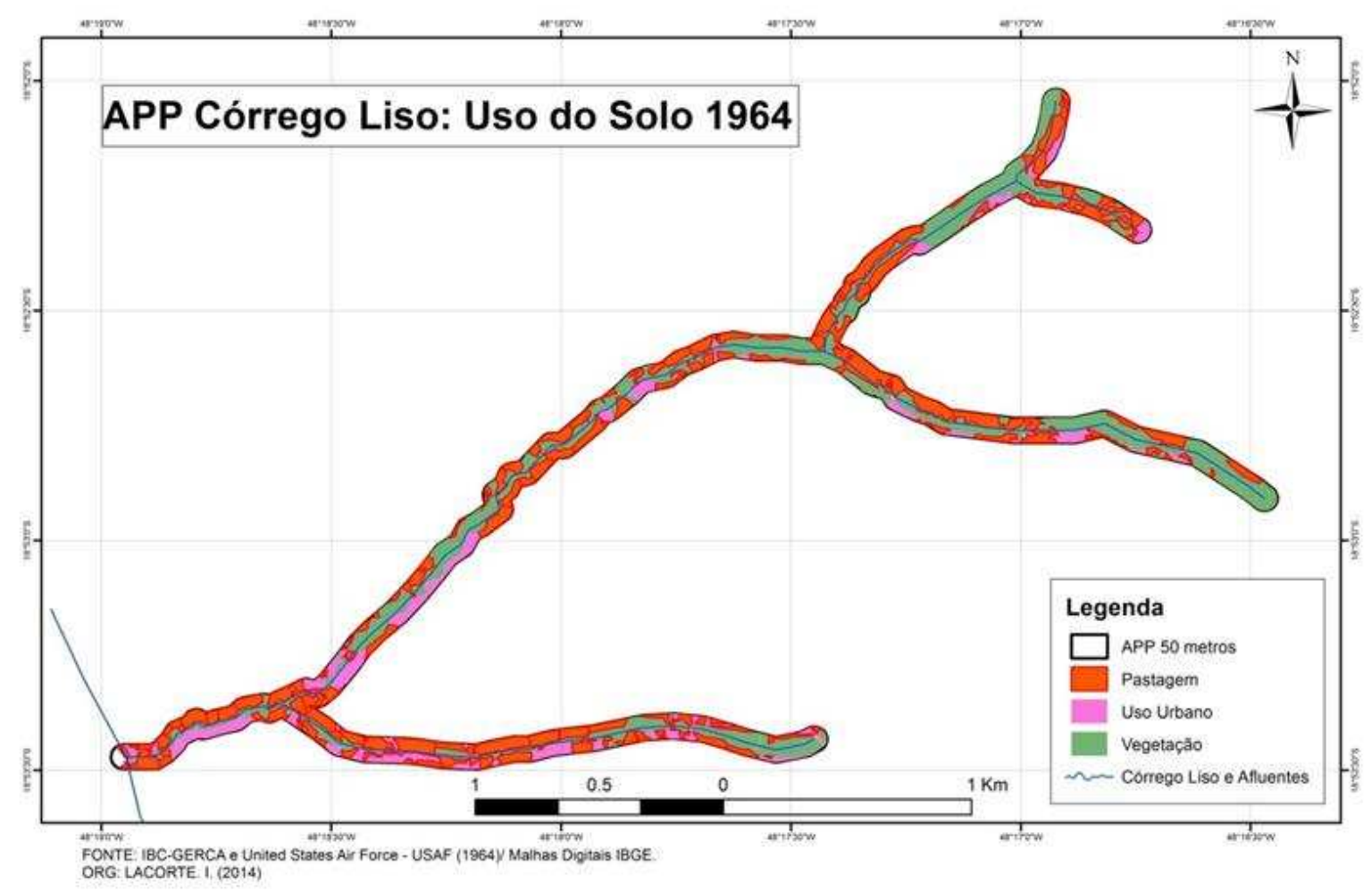

FIGURA 4- Uso do solo na Bacia do Córrego Liso em 1964. Fonte: As Autoras.

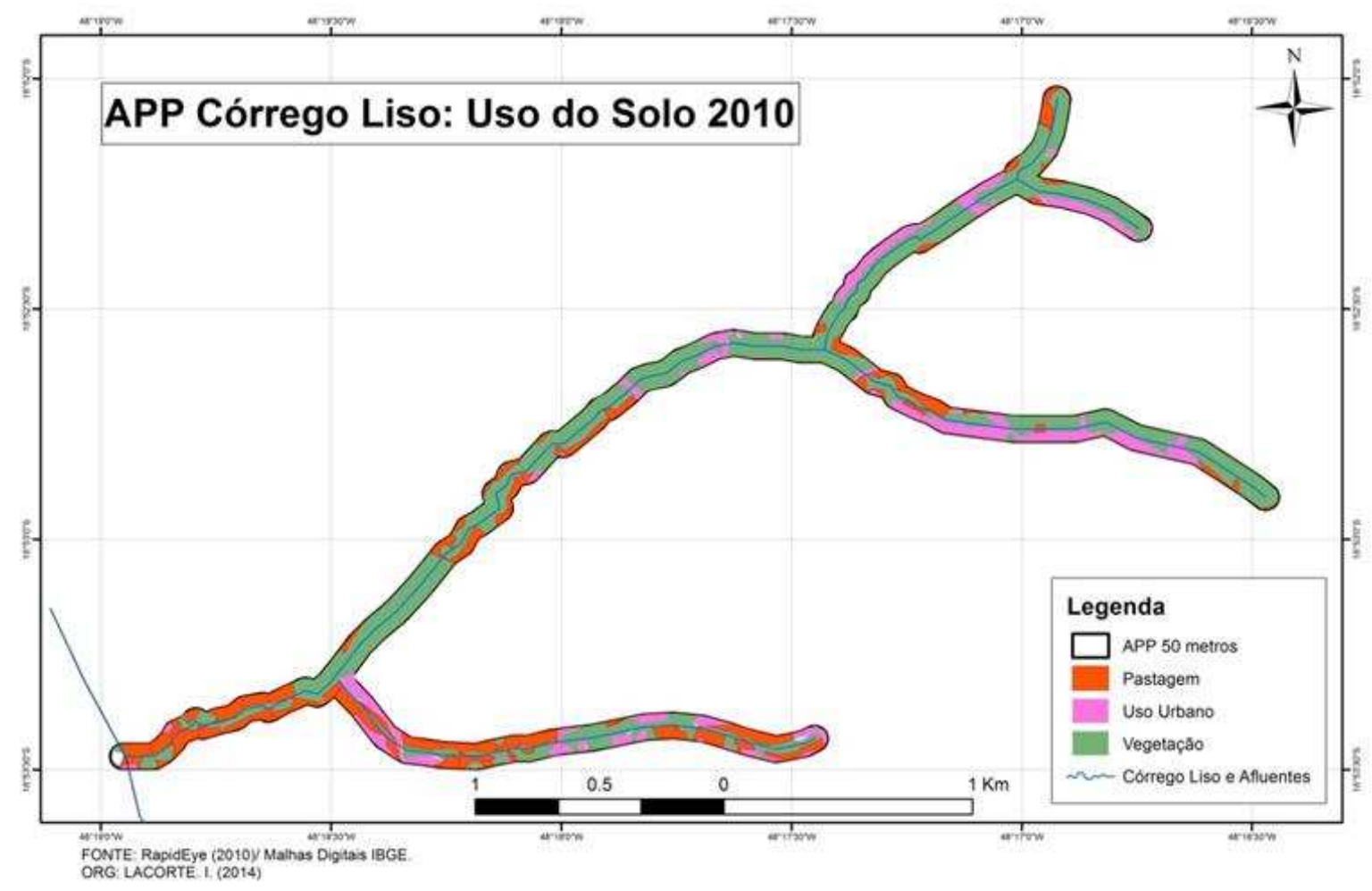

FIGURA 5- Uso do solo na Bacia do Córrego Liso em 2010. Fonte: As Autoras. 
A fim de comparar as diferenças na ocupação da bacia, na Figura 6 são apresentadas as porcentagens das áreas de cada classe de uso nos anos de $1964 \mathrm{e}$ 2010. Observa-se que a porcentagem de vegetação e a porcentagem de uso urbano cresceram de 1964 para 2010, sendo que a porcentagem de pastagem sofreu redução no mesmo período. Logo, pode-se dizer que a área ocupada por pastagem em 1964 deu espaço às classes de vegetação e urbanização em 2010.

O fato da área vegetada em 2010 ser maior do que em 1964 pode ser justificado pela implementação do Código Florestal em 1965, através da Lei Federal no 4.771 (BRASIL, 1965), e pela criação do Decreto Municipal no 7.452 instituído em 1997 (UBERLÂNDIA, 1997), em que foram criados os Parques Municipais de Uberlândia. No caso do córrego Liso, localizado próximo ao Bairro Industrial, foi criado o Parque Municipal Distrito Industrial, que de acordo com o inciso III do Art. 1 do decreto foi constituído de duas áreas verdes, de propriedade do Município de Uberlândia. Com isso, passou-se a preservar mais, no entanto, essas podem não ser as únicas justificativas, sendo necessárias outras investigações.

\section{Comparação das Classes nos anos de 1964 e 2010}

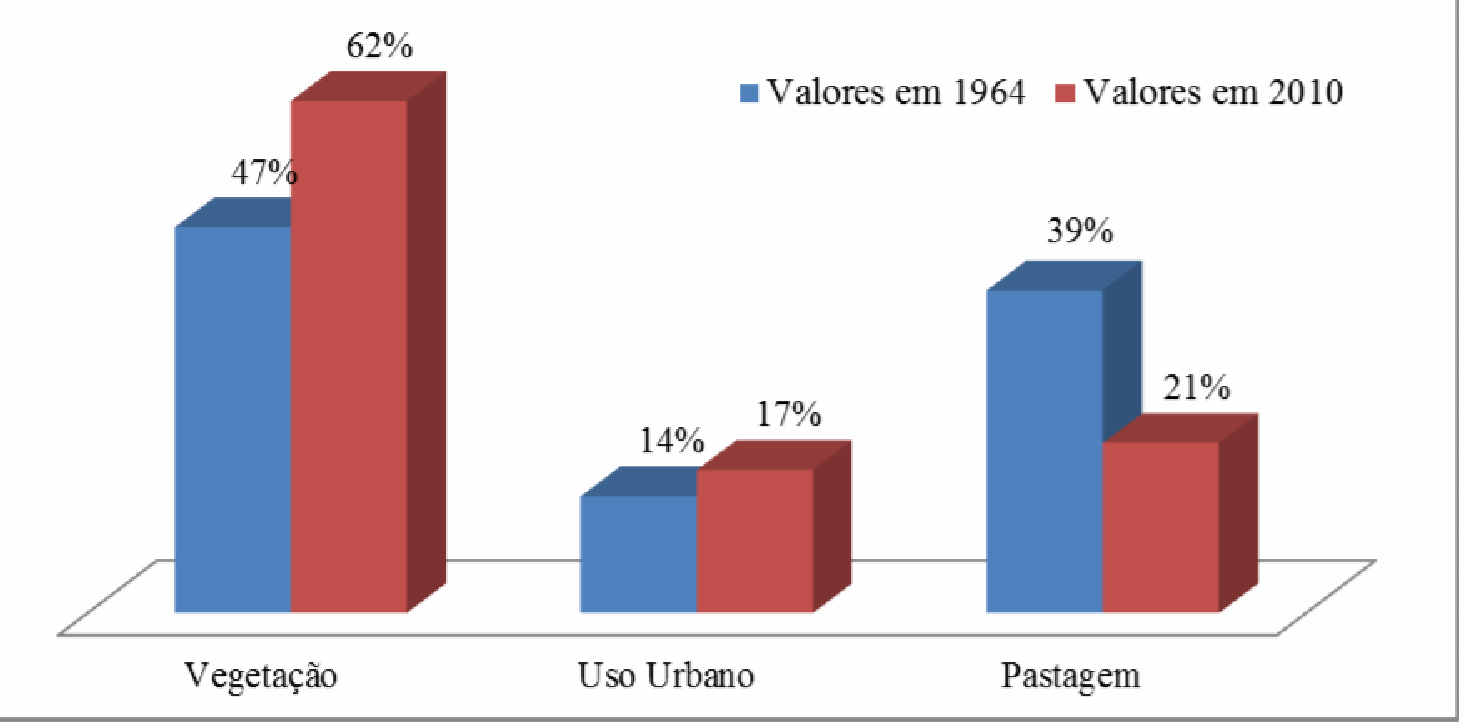

FIGURA 6- Comparação das classes de pastagem, uso urbano e vegetação em APP do Córrego Liso nos anos de 1964 e 2010. Fonte: As Autoras.

No ano de 2010, a área de vegetação representa maior porcentagem de ocupação dentro da bacia. No entanto, apesar das áreas vegetadas dentro das APPs hídricas (nascentes e margens de rio) terem aumentado no período analisado, 37,92\% das APPs ainda estão ocupadas por pastagens ou áreas urbanas em 2010.

Vale destacar que as APPs são áreas em que não é permitido desmatamento da vegetação, sendo chamadas de áreas intangíveis, isto é, destinadas à preservação dos recursos naturais, onde a vegetação não pode ser suprimida nem manejada. É permitido o acesso de pessoas e animais para obtenção de água, desde que não haja desmatamento e que a regeneração e a manutenção em longo prazo da vegetação nativa não sejam comprometidas (art. 4을 $\S 7^{\circ}$ da Lei Federal $n^{\circ}$ 12.651/2012). Em caso de degradação, as APPs devem ser recompostas pelo proprietário ou pelo Poder Público (art. 18 da Lei Federal n 12.651/2012). Ainda, a 
supressão total ou parcial de vegetação em APP pode ser autorizada somente em caso de utilidade pública e interesse social ou para aquelas atividades consideradas de baixo impacto ambiental, no entanto, com autorização prévia do órgão ambiental competente (art. 4 da Lei Federal no 12.651/2012). Essa autorização apenas será exonerada para atividades de segurança nacional e realização de obras de interesse para a defesa civil, as quais mitigariam acidentes possíveis das áreas urbanas. (BRASIL, 2012). Assim, como as áreas sem vegetação não representam atividades de utilidade pública e nem de interesse social, a ocupação de dois quintos da área de APP dentro da bacia do córrego Liso é irregular.

\section{Atividades Impactantes na APP da Bacia do Córrego Liso}

Diante da ocupação por pastagem ou áreas urbanas das áreas que deveriam estar vegetadas, torna-se pertinente verificar o que causa impactos dentro destas áreas que deveriam ser destinadas à preservação das funções ambientais. Em pesquisa de campo realizada no local do córrego Liso foram encontrados diversos fatores agravantes dos impactos causados às APPs, entre eles, instalações de moradias irregulares, com descarte de resíduos sólidos e líquidos no curso d'água. Em algumas instalações foi possível observar até criação de animais, como galinhas, dentro da área que deveria ser protegida. Ainda, observou-se parte do terreno com solo exposto.

Foram identificados também resíduos sólidos descartados incorretamente na margem do curso d'água. Estes resíduos eram, em sua maioria, resíduos domiciliares. Foi observado também problemas com despejo de efluentes, gerando contaminação da água do córrego, sendo que o efluente descartado pode ser domiciliar ou, ainda, de indústrias, o que seria um fator que agravaria mais a situação de impacto e poluição em que se encontra o córrego. Assim, as atividades industriais e a ocupação por moradias estão sendo as principais atividades geradoras de impacto nas APPs da bacia do córrego Liso. No caso das indústrias, fiscalizações mais rígidas por parte do órgão ambiental seria a possível solução para o problema.

Já a ocupação irregular por moradias apresenta maior complexidade. AMADO (2014) comenta que, no que diz respeito ao conflito entre o direito fundamental à moradia e o direito à preservação ambiental, a primeira análise a ser feita é se as pessoas possuem o direito de construir habitações irregularmente em áreas de preservação permanente, considerando-se o evidente processo de exclusão social e de favelização dos grandes centros urbanos brasileiros. De acordo com a legislação ambiental, é proibido esse tipo de interferência nessas áreas, no entanto, quanto ao direito de moradia digna dos seres humanos há uma discordância neste assunto, mesmo sendo essas regiões consideradas de perigo para habitação, pois são áreas vulneráveis.

De acordo com GONDIM (2012), na ausência de políticas públicas para tornar o uso e a ocupação do espaço urbano compatíveis com a justiça social e os requisitos do meio ambiente sustentável, a questão habitacional tem se revelado quase intratável. O mesmo autor considera que, mesmo antes da aprovação do Estatuto da Cidade, foram implantadas múltiplas e diversificadas políticas habitacionais, incluindo a urbanização de favelas. Entretanto, tais políticas têm sido incapazes de deter o crescimento de assentamentos informais com precárias condições de habitabilidade. Em algumas cidades como Fortaleza, quando a situação se torna emergente em relação à população se expandir para áreas de preservação, as quais são perigosas para moradia, devido à instabilidade, o governo 
pode interferir criando projetos habitacionais e uma ação como a Ação Civil Pública, para que a Prefeitura retire novos ocupantes da área, quando não há recursos suficientes para incluí-los como beneficiários do projeto habitacional. Neste caso, o governo emprega métodos de incentivos para que a população se instale em lugares adequados; no entanto, há aqueles que se aproveitam do incentivo, mas depois retornam às favelas com o benefício adquirido.

Entretanto, não são apenas populações carentes que desrespeitam o Código Florestal, assim como ANDRADE \& DAMIS (2006) afirmam, os condomínios residenciais de alto padrão têm sido construídos em áreas arborizadas e no entorno de lagoas, interferindo nas leis ambientais. Há ainda autor como BITTENCOURT (2008), que defende a ideia de que aqueles que apresentam melhor situação financeira são os mais atuantes no desmatamento de APP, devido a atividades como especulação imobiliária, como os condomínios de luxo citados anteriormente, mineração, pastagem e agricultura. Entretanto, o autor também encontra na procura pela necessidade de sobrevivência da população de menor poder aquisitivo, os impactos causados às APPs pela sua ocupação. ANDRADE \& DAMIS (2006) concluíram em seu trabalho que há um desacordo quando se trata de preservação do meio ambiente e o problema social de habitação, pois, como estabelece a lei, a destruição da vegetação em APP só é autorizada em casos de interesse social. Por isso, o governo deveria se empenhar para que não houvesse degradação do meio ambiente em favor de moradia.

\section{CONCLUSÃO}

A diferença na área de vegetação encontrada nas APPs mostra a intensidade dos impactos que estas sofrem ao longo do tempo, e as diferenças das preocupações sociais de cada época, sendo possível avaliar a aplicabilidade das APPs em áreas urbanas, mais especificamente no município de Uberlândia.

Comparando a situação de preservação da APP no ano de $2010 \mathrm{com}$ a situação encontrada no ano de 1964, percebeu-se que houve um melhoramento da área, já que durante esses anos a área de vegetação aumentou em $30,82 \%$. No entanto, mesmo com esse aumento, no ano de 2010, dois quintos da área de APP ainda se encontra ocupada por pastagem ou área urbana.

Esse déficit de quantia de vegetação encontrado dentro da APP reflete os impactos causados a essas áreas, tais como o despejo de entulho de construção civil, a ocupação irregular da área, os despejos líquidos e sólidos e a poluição do ar. Esta última é ocasionada devido à localização do córrego entre indústrias, o que dificulta os processos biológicos naturais de regeneração do meio ambiente.

Assim, torna-se imperativo a instituição de legislações mais rígidas; maiores fiscalizações nas áreas, impedindo despejos irregulares, tanto sólidos como líquidos; desapropriação da população ali instalada, e realocação em uma área mais adequada; e o desenvolvimento de planos de recuperação da parte impactada da área, será possível obter uma área de APP bem preservada e com boa qualidade ambiental, tornando viável a presença de APP em áreas urbanas.

\section{REFERÊNCIAS}

AMADO, F. A. T. Direito Ambiental Esquematizado. 5. Ed. Rio de Janeiro: Forense. 2014. 
ANDRADE, T. S.; DAMIS, R. C. B. A inaplicabilidade do Código Florestal em área urbana. Revista Brasileira de Direito Ambiental, v. 2, p. 121-144, 2006.

ARAUJO, S. M. V. G. As áreas de preservação permanente e a questão urbana: estudo técnico consultoria legislativa da área de meio ambiente, direito ambiental, organização territorial, desenvolvimento urbano e regional. Brasília, DF: [s.n.], 2002. 12p.

BITTENCOURT, L. F. F. Análise Sócio-Ambiental da Ocupação Urbana da Área de Preservação Permanente do Rio Paraíba do Sul no Município de Caçapava, SP. Dissertação (Mestrado em Ciências Ambientais). Universidade de Taubaté. 50 p. 2008.

BONHAM-CARTER, G. F. Geographic Information Systems for Geoscientists: Modelling with GIS. Ottawa: Pergamon. 398 p, 1996.

BORSOI, V.; JUNIOR, R. A. N. Análise Multitemporal da Expansão da Urbana em Área de Proteção Permanente no Município de Caçapava- SP. Simpósio Brasileiro de Sensoriamento Remoto, Natal, Brasil, abril 2009. p.609-616. Universidade de Taubaté- Unitau. 2009.

BRASIL. Lei no 4.771, de 45 de Setembro de 1965. Disponível em:<http://www.planalto.gov.br/ccivil_03/Leis/L4771.htm> Acesso em: 08 out. 2013.

BRASIL. Lei no 12.651, de 25 de Maio de 2012. Disponível em:<http://www.planalto.gov.br/ccivil_03/_Ato2011-2014/2012/Lei/L12651.htm> Acesso em: 08 out. 2013.

ELACHI, C. Introduction to the Physics and Techniques of Remote Senseing, Nova York: Wiley. 1987.

FORNO, M. A. R. D. Os conflitos de Uso e Ocupação Urbana em áreas de Preservação Permanente- APPs. Tese (Doutorado Ciências Humanas) Universidade Federal do Rio Grande do Sul- Instituto de Geociências. Pósgraduação em Geografia.113p. 2009.

GONDIM, L. M. P. Meio Ambiente Urbano e Questão Social: habitação popular em áreas de preservação ambiental. Caderno CRH, v. 25, n.64, p.15-130, 2012.

HOGAN, D. J. Redistribuição da População e Meio Ambiente: São Paulo e Centro-oeste. Dinâmica Demográfica e Mudança Ambiental. Publicações Nepo. Campinas-SP. 2006.

IBGE - Instituto Brasileiro de Geografia e Estatística. Tendências Demográficas. $2002 . \quad$ Disponível em: <http://cidades.ibge.gov.br/painel/painel.php?codmun=317020> Acesso em: 17 fev. 2014.

LONGLEY, P. A.; MAGUIRE, D. J.; GOODCHILD, M. F., RHIND, D. W. Sistemas e Ciência da Informação Geográfica. 3. Ed. Porto Alegre: Bookman. 2013. 
PERES, R. H. B., O Caminho das Águas: Impacto Ambiental das Drenagens de Água Pluvial na Bacia do Córrego Liso na Cidade de Uberlândia - MG. Dissertação (Mestrado) - Instituto de Geografia. Universidade Federal de Uberlândia. 204 p. 2005.

RELATÓRIO DE BRUNDTLAND. Our Common Future. Disponível em: $<$ http://ambiente.files.wordpress.com/2011/03/brundtland-report-our-commonfuture.pdf> Acesso em: 26 dez. 2013.

SCHNEIDER, M. O. Bacia do Rio Uberabinha: Uso agrícola do solo e meio ambiente. Tese (Doutorado em Geografia) - Departamento de Geografia da Faculdade de Filosofia, Letras e Ciências Humanas, Universidade de São Paulo. São Paulo, 157 p. 1996.

SILVA, M. D. A Vereda do Córrego Liso em Uberlândia-MG. Monografia- Instituto de Geografia, Universidade Federal de Uberlândia. 94 p. 2006.

UBERLÂNDIA. Decreto no 7.452, de 27 de Novembro de 1997. Disponível em: < http://www.uberlandia.mg.gov.br/uploads/cms_b_arquivos/2563.pdf> Acesso em: 26 dez. 2013. 